\title{
Fate of Abstracts Presented at the Korean College of Rheumatology Annual Scientific Meetings
}

\author{
Yong-Gil Kim ${ }^{1}$, Chan-Bum Choi $^{2}$, Seong Wook Kang ${ }^{3}$, Jinseok Kim ${ }^{4}$, Young Dae Kim ${ }^{5}$, Jaejoon Lee ${ }^{6}$, Myeung Su Lee ${ }^{7}$ \\ Young-Ho Lee ${ }^{8}$, Jun-Ki Min ${ }^{9}$, Min-Chan Park ${ }^{10}$, Sung Hoon Park ${ }^{11}$, Yong-Wook Park ${ }^{12}$, Seung Wook Lee ${ }^{13}$, Jae-Bum Jun ${ }^{2}$ \\ ${ }^{1}$ Division of Rheumatology, Department of Internal Medicine, Asan Medical Center, University of Ulsan College of Medicine, ${ }^{2}$ Department of \\ Rheumatology, Hanyang University Hospital for Rheumatic Diseases, Seoul, ${ }^{3}$ Department of Internal Medicine, Chungnam National University \\ School of Medicine, Daejeon, ${ }^{4}$ Department of Internal Medicine, Jeju National University Hospital, Jeju, ${ }^{5}$ Department of Pediatrics, Ilsan Paik \\ Hospital, Inje University College of Medicine, Goyang, ${ }^{6}$ Division of Rheumatology, Department of Medicine, Samsung Medical Center, \\ Sungkyunkwan University School of Medicine, Seoul, ${ }^{7}$ Division of Rheumatology, Department of Internal Medicine, Wonkwang University \\ Hospital, Iksan, ${ }^{8}$ Division of Rheumatology, Department of Internal Medicine, Korea University College of Medicine, ${ }^{9}$ Division of Rheumatology, \\ Department of Internal Medicine, College of Medicine, The Catholic University of Korea, ${ }^{10}$ Division of Rheumatology, Department of Internal \\ Medicine, Gangnam Severance Hospital, Yonsei University College of Medicine, Seoul, ${ }^{11}$ Division of Rheumatology, Department of Internal \\ Medicine, Arthritis and Autoimmunity Research Center, Catholic University of Daegu School of Medicine, Daegu, ${ }^{12}$ Department of \\ Rheumatology, Chonnam National University Medical School and Hospital, Gwangju, ${ }^{13}$ Department of Urology, Hanyang University Guri \\ Hospital, Guri, Korea
}

Objective. To evaluate the fate of abstracts presented at scientific meetings of the Korean College of Rheumatology (KCR). Methods. This study examined the abstracts presented at annual meetings of the KCR from 2005 to 2014. Only original studies were selected, excluding case reports. A manual search was conducted using PubMed, KoreaMed, Cochrane Library, and Embase to track the published articles. The abstracts were considered to have been published if the authors, title, study design, and results were the same for a published article. In addition, they were considered published if the author and the study design matched, even if the results of the abstract and the results of the published articles were not identical. Results. A total of 928 abstracts from 2005 to 2014 were analyzed. Of the 928 abstracts, 468 (50.43\%) abstracts were published in a peer-reviewed journal and the mean time to publication was 19 months. Of the 468 abstracts, 414 were published in a science citation index extended (SCI[E]) journal, and 54 were published in non- $\mathrm{SCl}(\mathrm{E})$ journals. The proportion of $\mathrm{SCl}(\mathrm{E})$ articles increased annually. The average impact factor for the $\mathrm{SCl}(\mathrm{E})$ journals was 2.93. In subgroup analysis, the abstracts that were awarded the best oral or best poster presentation were more likely to be published as full-length articles with a higher impact factor than the abstracts not awarded. Conclusion. Half of the abstracts presented in the KCR annual meetings were published in a peer-reviewed journal. Approximately $90 \%$ of the articles were published in a $\mathrm{SCI}(\mathrm{E})$ journal. (J Rheum Dis 2019;26:41-45)

Key Words. Abstract, Publication, Rheumatology, Korea

\section{INTRODUCTION}

The Korean College of Rheumatology (KCR), previously called the Korean Rheumatology Association, was organized 37 years ago. Since then, rheumatology has been recognized as a special field in Korea. According to a recent study [1], membership of the KCR has increased annually, reaching almost 800 member this year.
The academic conference of KCR is held every year in spring, reaching 38th in 2018, and provides an opportunity for rheumatologists, immunologists, orthopedics, pediatricians, and related health care professionals in Korea to share knowledge by gathering relevant medical issues, and exchanging recent experience and scientific information. In particular, the abstracts presented at academic conferences have implications on the experience

Received : September 20, 2018, Revised : October 26, 2018, Accepted : November 1, 2018

Corresponding to : Jae-Bum Jun ib http://orcid.org/0000-0002-0208-0505

Department of Rheumatology, Hanyang University Hospital for Rheumatic Diseases, 222 Wangsimni-ro, Seongdong-gu, Seoul 04763, Korea. E-mail : junjb@hanyang.ac.kr 
and knowledge of each practitioner. In addition, the abstract has been published in a medical or scientific journal and plays an important role in sharing the latest knowledge. On the other hand, a large number of abstracts cannot be published as papers due to the lack of data, statistical limitations, and lack of originality.

In 1980, the first study revealing the fate of abstracts was published in The New England Journal of Medicine [2]. Goldman and Loscalzo [2] selected 276 cardiology abstracts published in conjunction with three national meetings and reported that approximately $50 \%$ of abstracts led to full-length articles in peer-reviewed journals and the median interval between publication of the abstract was 14 months. In a Cochrane review of 46 studies, the publication rate of abstracts was a median of $45 \%$ (ranging from $11 \%$ to $78 \%$ ) [3]. In a recent study [4], the overall 2- and 5-year publication rates of abstracts presented at major international ophthalmology conferences were $33.3 \%$ and $47.2 \%$, respectively. Furthermore, a total of 538 abstracts presented at the European Association for Palliative Care (EAPC) congress meeting in 2005 were analyzed to determine the publication rate and the time to publish [5]. Of these, $43 \%$ of abstracts were published as a full-length article in peer-reviewed journals. Approximately one fifth of articles were published within 6 months, a quarter within 12 months, and $39 \%$ within 36 months of the presentation at the EAPC conference. In Korea, abstracts presented at the conference of Korean Urological Association (KUA) were analyzed. Approximately $40 \%$ of abstracts were published as full-length articles and it took 19 months on average for them to be published in a journal [6].

Over the past decade, the academic activities of KCR members have grown [1]. Therefore, an objective evaluation of the competence of the members of the society is needed. No prior study has evaluated the quality of KCR scientific meetings until now. This study evaluated the quality by analyzing the rate of publication of abstracts presented at the annual scientific meetings of the KCR.

\section{MATERIALS AND METHODS}

The subsequent publication rate of the 928 abstracts presented at the KCR conferences from 2005 to 2014 as full-length articles was evaluated because it was estimated that the time to publish was mostly within three years according to similar studies [2,5,6]. A manual search was conducted using PubMed, KoreaMed, Cochrane
Library, and Embase. The affiliations (universities or hospitals) and author names of each abstract were searched. Only full-length articles, excluding case reports, letters, reviews, and editorials, were selected. The article was considered published if the author, title, study design, and results were the same in the abstract and article. Even when the results of the abstract and articles published were somewhat different, the abstracts were considered published if the author and study design were similar. If the abstract presented in the KCR conference was determined to be published as an article, the published journal, journal impact factor (IF), publication time, and publication year were examined.

The articles published were classified into the science citation index (SCI) or SCI extended (SCIE) journal, and non-SCI(E) journal according to the Web of Science (Clarivate Analytics, Philadelphia, PA, USA) and the IF was established according to InCites Journal Citation Reports (Clarivate Analytics).

The percentage of abstracts that were subsequently published as full-length articles was calculated. The rate of publication and classification of the published journal according to years were analyzed using a Chi-square test. ANOVA was used to determine the time elapsed until publication and the IF of the published journal. For data analysis, PASW statistical software, version 18.0 (IBM Corp., Armonk, NY, USA) was used and a p-value $<0.05$ was considered significant.

\section{RESULTS}

Of the 928 abstracts presented at KCR annual scientific

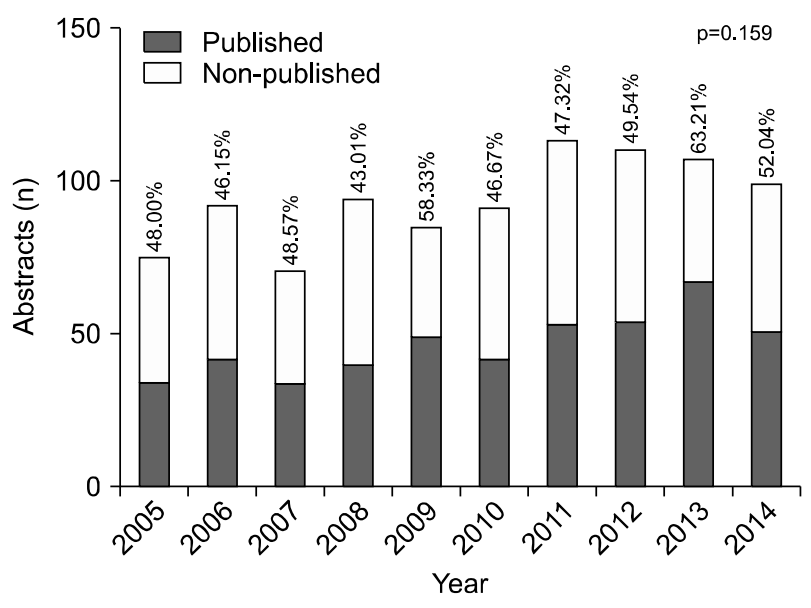

Figure 1. Annul publication rate as a full-length article. Chi-square test. 
meetings from 2005 to 2014, 468 abstracts (50.43\%) were identified as full-length articles in peer-reviewed journals. There was no abstract presented by foreigner during that period. As shown in Figure 1, there was no significant difference in the rate of articles published annually. The rate of publication ranged from $43.01 \%$ (2008) to $63.21 \%$ (2013). The time from the abstract to article publication was $19.42 \pm 16.79$ months, and there was no difference in the time taken for publication in each year (data not shown).

As shown in Table 1, among the 468 articles published, $414(88.46 \%)$ were published in SCI or SCIE journals, and 54 (11.54\%) were published in non-SCI(E) journals. That is, almost $45 \%$ of the abstracts presented at KCR scientific meetings were applied to the SCI(E) journals. An increase in the proportion of SCI(E) journals over time was noted. An examination of the IF of the year in which the article was published in the SCI(E) journal revealed a mean IF score of $2.93 \pm 1.83$, which was similar in each year (Table 2).

Through a fair examination of the academic affairs committee and publication committee of KCR, $10 \%$ of abstracts had been awarded annually as the best oral pre-

Table 1. Proportion of the $\mathrm{SCl}(\mathrm{E})$ journals published annually

\begin{tabular}{cccc}
\hline \hline Year & SCl(E) & Non-SCl(E) & p-value* \\
\hline 2005 & $28(77.78)$ & $8(22.22)$ & $<0.001$ \\
2006 & $34(80.95)$ & $8(19.05)$ & \\
2007 & $32(94.12)$ & $2(5.88)$ & \\
2008 & $29(72.50)$ & $11(27.50)$ & \\
2009 & $43(87.76)$ & $6(12.24)$ & \\
2010 & $34(80.95)$ & $8(19.05)$ & \\
2011 & $50(94.34)$ & $3(5.66)$ & \\
2012 & $48(88.89)$ & $6(11.11)$ & \\
2013 & $66(98.51)$ & $1(1.49)$ & \\
2014 & $50(98.04)$ & $1(1.96)$ & \\
Total & $414(88.46)$ & $54(11.54)$ & \\
\hline
\end{tabular}

Values are presented as number (\%). SCl: science citation index, $\mathrm{SCl}(\mathrm{E}), \mathrm{SCl}$ extended. ${ }^{*}$ Chi-square test. sentation or best poster presentation. In subgroup analysis (Table 3), the 84 abstracts awarded the best oral presentation or best poster presentation, were more likely to be published compared to the 844 abstracts not awarded $(p=0.008)$. Interestingly, the IF of articles which had best oral presentation $(4.21 \pm 2.52)$ or best poster presentation $(3.32 \pm 1.75)$, showed a higher IF than those not awarded $(2.83 \pm 1.74)(\mathrm{p}<0.001)$ (Table 4$)$.

As shown in Table 5, among the journals that published the 468 abstracts as full-length articles, the most frequent was Rheumatology International (9.19\%), followed in order by the Journal of Rheumatic Diseases (JRD), which is the official journal of the KCR (8.33\%), and Journal of Rheumatology (7.26\%). The abstracts presented at KCR conferences were published in foreign journals (77.78\%) and domestic journals (22.22\%), including JRD, Korean Journal of Internal Medicine, and Journal of Korean Medical Science.

\section{DISCUSSION}

Several years ago, global scientific progress in the field of

Table 2. Impact factor of $\mathrm{SCI}(\mathrm{E})$ journals published annually

\begin{tabular}{cccc}
\hline \hline Year & SCI(E) & Impact factor & p-value* \\
\hline 2005 & 28 & $3.14 \pm 2.24$ & 0.34 \\
2006 & 34 & $2.96 \pm 1.91$ & \\
2007 & 32 & $3.35 \pm 1.67$ & \\
2008 & 29 & $2.85 \pm 1.06$ & \\
2009 & 43 & $3.07 . \pm 2.21$ & \\
2010 & 34 & $2.12 \pm 0.90$ & \\
2011 & 50 & $2.94 \pm 1.77$ & \\
2012 & 48 & $3.17 \pm 2.12$ & \\
2013 & 66 & $2.91 \pm 2.05$ & \\
2014 & 50 & $2.77 \pm 1.50$ & \\
Total & 414 & $2.93 \pm 1.83$ &
\end{tabular}

Values are presented as number only or mean \pm standard deviation. $\mathrm{SCl}$ : science citation index, $\mathrm{SCl}(\mathrm{E})$ : $\mathrm{SCl}$ extended. *ANOVA.

Table 3. Fate of abstracts that win awards

\begin{tabular}{lrrrr}
\hline \hline & Total & Articles & SCI(E) & p-value* \\
\hline No award & 844 & $412(48.81)$ & $364(43.12)$ & 0.008 \\
Best poster presentation & 43 & $29(67.44)$ & $23(53.49)$ & \\
Best oral presentation & 41 & $27(65.85)$ & $27(65.85)$ & \\
Total & 928 & $468(50.43)$ & $414(44.61)$ & \\
\hline
\end{tabular}

Values are presented as number only or number (\%). SCl: science citation index, $\mathrm{SCl}(\mathrm{E})$ : $\mathrm{SCl}$ extended. ${ }^{*} \mathrm{Chi}-\mathrm{square}$ test. 
Table 4. Impact factor of articles dependent on a type of award

\begin{tabular}{lrcc}
\hline \hline & $\mathrm{SCl}(\mathrm{E})$ & Impact factor & $\mathrm{p}^{\text {-value }}{ }^{\dagger}$ \\
\hline Not awarded & 364 & $2.83 \pm 1.74$ & \\
Best poster presentation & 23 & $3.32 \pm 1.75$ & $0.321^{\dagger}$ \\
Best oral presentation & 27 & $4.21 \pm 2.52$ & \\
Total & 414 & $2.93 \pm 1.83$ & \\
p-value* $^{*}$ & & $<0.001$ & \\
\hline
\end{tabular}

Values are presented as number only or mean \pm standard deviation. $\mathrm{SCl}$ : science citation index, $\mathrm{SCl}(\mathrm{E})$ : $\mathrm{SCl}$ extended. *ANOVA between best poster presentation vs. best oral presentation, impact factor. ${ }^{\dagger}$ Mann Whitney test.

rheumatology was measured by an evaluation of the number of the publications of rheumatologists between 2000 and 2011 [7]. In 2000, the number of papers published was 3,278; this number has increased annually, reaching 7,461 in 2011, a more than 2-fold increase. On the other hand, Korea was not included in the top 10 countries (ranking in the order of USA, England, Germany, Netherlands, Italy, Japan, France, Canada, Sweden, and Switzerland) publishing papers. At this point, it is important to evaluate the scientific competence of KCR members through objective indicators.

Between 2005 and 2014, a total of 50.43\% of abstracts presented at KCR annual conferences were published as full-length articles. The rate of publication appears to be superior to previous studies $[3,4,6]$. Furthermore, the rate of publication in SCI(E) journals was $88 \%$ of the total journals published, which has increased annually. These findings suggest that the abstracts released at the KCR annual meetings are comparable to the global standard and that the research activities of KCR members are also excellent.

In a recent study of the Romanian Society of Gastroenterology and Hepatology, only $10 \%$ of abstracts presented at the 2013 and 2014 meetings were published as full-length articles in indexed journals [8]. They mentioned that Romania is a non-native English-speaking region, which was the reason for the low publication rate. Indeed, the publication rate of abstracts presented at an international emergency medicine meeting was different between native English-speaking countries and non-native English-speaking countries (36.9\% vs. 18.8\%) [9]. Considering that Korea is a non-native English-speaking country, the high publication rate in the present study highlights the excellent scholarship of the members.

Although publication media and open-assess policy
Table 5. List of journals published as full-length articles

\begin{tabular}{lc}
\hline \multicolumn{1}{c}{ Journals } & Articles \\
\hline Rheumatology International & $43(9.19)$ \\
Journal of Rheumatic Diseases* & $39(8.33)$ \\
Journal of Rheumatology & $34(7.26)$ \\
Arthritis Research \& Therapy & $25(5.34)$ \\
Korean Journal of Internal Medicine & $25(5.34)$ \\
Arthritis and Rheumatology & $22(4.70)$ \\
Journal of Korean Medical Science & $20(4.27)$ \\
Clinical and Experimental Rheumatology & $19(4.06)$ \\
Rheumatology (Oxford) & $18(3.85)$ \\
International Journal of Rheumatic Diseases & $17(3.63)$ \\
Clinical Rheumatology & $17(3.63)$ \\
Journal of Immunology & $12(2.56)$ \\
Lupus & $12(2.56)$ \\
Immunology Letters & $11(2.35)$ \\
Scandinavian Journal of Rheumatology & $8(1.71)$ \\
Modern Rheumatology & $7(1.50)$ \\
PLOS One & $7(1.50)$ \\
Inflammation Research & $6(1.28)$ \\
Joint Bone Spine & $6(1.28)$ \\
Others & $120(25.60)$ \\
Total & 468 \\
\hline Values are presented as number (\%). &
\end{tabular}

Values are presented as number (\%). *Official journal of Korean College of Rheumatology.

could influence the journal citation rate, the IF is generally used as a criterion to evaluate the quality of an article and to assess the research competence of a research team or individual [10]. In a previous study in the field of radiation oncology in Korea, the average IF was 2.9 for all published SCI(E) journals written by members of the Korean Society of Radiation Oncology from 1981 to 2011 and the average IF tend to decrease with years [11]. In the present study, the overall mean IF was 2.93 when the IF of the year in which the abstract was published in the $\mathrm{SCI}(\mathrm{E})$ journal was analyzed, and the IF was not different over time. Interestingly, all articles awarded the best oral presentation were more likely to be published in a SCI(E) journal and the IF $(4.21 \pm 2.52)$ was higher than that $(2.83 \pm 1.74)$ of articles not awarded. This type of analysis is the first to the authors' knowledge, and it is believe that it could be a standard to evaluate the methodological relevance of whether the abstracts awarded are qualified scientifically.

In a similar study performed in Korea [6], most abstracts were published in the Korean Journal of Urology (57.5\%), which is the official journal of the KUA. In the present study, however, only $8.3 \%$ of abstracts were published in 
the JRD, the official journal of KCR, because it was not a $\mathrm{SCI}(\mathrm{E})$ journal and comprised mainly of case reports during the period of study. Recently, the JRD has been renovated to meet the international standards of peer-reviewed journals. Since 2016, articles of the JRD have been published in English only and comprised mainly of full-length articles. The editors of JRD believe that incorporation in a SCI(E) journal in the future will be necessary for many KCR members to contribute a good article to their official journal.

The limitations of the present study include the possibility of missed published articles because a manual search was conducted. Moreover, some abstracts could have been unmatched if the study design had changed when it was published in a journal. On the other hand, the present study is valuable in that it reflects the high scientific quality of the KCR annual meetings for a long time.

\section{CONCLUSION}

Half of the abstracts presented at the scientific meetings of the KCR from 2005 to 2014 were published as fulllength articles in peer-reviewed journals. Approximately $90 \%$ of full-length articles were published in the SCI(E) journal, and this ratio has increased over time. Based on our results, the quality of abstracts presented at the KCR annual meetings reaches sufficiently to the international standard.

\section{ACKNOWLEDGMENTS}

This work was supported by the research fund of the Korean College of Rheumatology (KCR-2018-01).

\section{CONFLICT OF INTEREST}

No potential conflict of interest relevant to this article was reported.

\section{REFERENCES}

1. Kim HY, Song YW. The dynamic evolution of rheumatology in Korea. Nat Rev Rheumatol 2016;12:183-9.

2. Goldman L, Loscalzo A. Fate of cardiology research originally published in abstract form. N Engl J Med 1980;303: 255-9.

3. Scherer RW, Langenberg P, von Elm E. Full publication of results initially presented in abstracts. Cochrane Database Syst Rev 2007; (2):MR000005.

4. Villani E, Vujosevic S, Specchia C, Tresca Carducci F, De Cillà $S$, Nucci $P$. The fate of abstracts presented at international ophthalmology meetings: 2- and 5-year publication rates. Eur J Ophthalmol 2018 Jul 1 [Epub]. DOI: 10.1177/ 1120672118784802.

5. Hanchanale SV, Jordan A. From abstract to publication: the fate of research presented at the European Association for Palliative Care Congress Meeting. Palliat Med 2014;28: 534-5.

6. Chung JH, Autorino R, Kang DH, Lee JY, Moon HS, Choi $\mathrm{HY}$, et al. Fate of abstracts presented at the annual meeting of the Korean Urological Association. Korean J Urol 2012; 53:280-4.

7. Tezcan ME. Overview of the publications of rheumatologists after the millennium. Eur J Rheumatol 2015;2:96-8.

8. Trifan A, Chihaia CA, Tanase O, Lungu CM, Stanciu C. The fate of abstracts presented at the 2013 and 2014 annual meetings of the Romanian Society of Gastroenterology and Hepatology. J Gastrointestin Liver Dis 2016;25:533-6.

9. Chan JW, Graham CA. Full text publication rates of studies presented at an International Emergency Medicine Scientific Meeting. Emerg Med J 2011;28:802-3.

10. Oh J, Chang H, Kim JA, Choi M, Park Z, Cho Y, et al. Citation analysis for biomedical and health sciences journals published in Korea. Healthc Inform Res 2017;23: 218-25.

11. Park W, Huh SJ. Current status and trend of the publication to the SCI and SCIE journals in the field of radiation oncology in Korea for 30 years. Radiat Oncol J 2012;30:14-9. 